\title{
Interannual Variability of the Rainy Season and Rainfall in the Brazilian Amazon Basin
}

\author{
BRANT LIEBMANN \\ NOAA-CIRES Climate Diagnostics Center, Boulder, Colorado \\ José A. MAREngo \\ Centro de Previsão de Tempo e Estudos Climáticos, Cachoeira Paulista, São Paulo, Brazil
}

(Manuscript received 29 January 2001, in final form 15 June 2001)

\begin{abstract}
Interannual variability of seasonal rainfall in the Brazilian Amazon basin is examined in context of its relationship to sea surface temperatures in the tropical Pacific and Atlantic Oceans. Linear correlations reveal strong relationships, but rainfall patterns are of regional scale. Areas of rainfall exhibiting strong relationships with SST are confined to the equatorial region of the Brazilian Amazon. The best relationships are found either during the season of transition between wet and dry regimes, or entirely within the dry season. It is hypothesized, and results are shown in support, that during the transition seasons, an important contributor to the SST control on seasonal totals is its influence on the timing on the rainy season onset or end. That influence appears to be stronger than the SST influence on the rainy season rain rate.
\end{abstract}

\section{Introduction}

The point of this paper is to present evidence that the timing of the rainy season (i.e., variation of the start and end dates) is an important contributor to seasonal total rainfall, and that where sea surface temperatures (SSTs) influence seasonal total rainfall, it is often through their influence on the timing, rather than on the rate of precipitation during the rainy season. While the first statement seems rather obvious (a short rainy season is often dry), this point seems to have been overlooked in many studies of general circulation model (GCM) simulated rainfall, which tend to concentrate on how well they can reproduce seasonal totals without regard to rainy season timing.

Although the annual cycle dominates convection over the Americas (e.g., Horel et al. 1989), with convection to a first approximation following the sun, interannual variability is not negligible. Most studies of interannual variability of Amazon rainfall have focused on anomalies associated with the El Niño-Southern Oscillation (ENSO) phenomenon (Kousky et al. 1984; Kayano and Moura 1986; Aceituno 1988; Ropelewski and Halpert 1987, 1989; Rogers 1988; Kiladis and Diaz 1989; Kousky and Ropelewski 1989; Rao and Hada 1990; Figueroa and Nobre 1990; Obregon and Nobre 1990; Marengo

Corresponding author address: Brant Liebmann, Climate Diagnostics Center, R/CDC1, 325 Broadway, Boulder, CO 80303-3328. E-mail: bl@cdc.noaa.gov
1992, 1995; Marengo and Hastenrath 1993; Rao et al. 1996; Marengo and Nobre 2000, Fu et al. 2001). The low phase of the Southern Oscillation (SO), associated with El Niño, coincides with reduced Amazon rainfall, especially in the northern and central regions, while opposite anomalies often occur during the high phase of the SO (associated with La Niña). The poor rainy seasons of 1925/26, 1982/83, and 1997/98 occurred during an El Niño, with the later considered as being the driest in the last 118 years (Marengo and Nobre 2000). Wetter than average conditions were observed during the La Niña years of $1988 / 89$ and 1995/96. During El Niño, anomalous ascending motion over the eastern equatorial Pacific is thought to produce anomalous subsidence east of the Andes, resulting in below-average precipitation in the northern Amazon during those events (e.g., Marengo and Hastenrath 1993). On the other hand, most of the interannual variance of rainfall in Amazonia is not explained by ENSO (e.g., Marengo et al. 1993; Rao et al. 1996; Marengo et al. 2001; Dettinger et al. 2000).

Although the role of the Pacific has been emphasized in studies of the association between SST and Amazon rainfall, the Atlantic Ocean appears to influence rainfall as well. Marengo (1992) and Rao et al. (1996) showed that increased rainfall in the Amazon is associated with an increase of water vapor transport from the Atlantic. Wagner (1996) showed that an enhanced meridional gradient of tropical SST in the Atlantic, with warm waters to the south, favors increased rainfall in northeast Brazil. 
While onset of the rainy season in the Amazon has not been examined in relation to seasonal rainfall totals, it has been recognized as important in its own right (i.e., to many practical applications, especially agriculture). Kousky (1988) described the spatially varying climatological onset and end using outgoing longwave radiation (OLR). Horel et al. (1989), also using OLR, examined interannual variability of onset and end of the rainy season over tropical South America as a whole. From composite analyses, Horel et al. found that the Bolivian high and a downstream trough develop rapidly during onset.

In the Amazon basin, Marengo et al. (2001), using pentad averages of gauge-based rainfall observations, did not find a large composite wind signal about onset, suggesting that onset is controlled by large-scale thermodynamic conditions, especially in the southern Amazon (Fu et al. 1999). They did, however, find relationships between tropical SST and onset and end in the central Amazon and near the mouth of the Amazon River. SST anomalies were not found to be related to the timing of onset in the southern Amazon. Both of these findings are consistent with the arguments of $\mathrm{Fu}$ et al. (1999) that near the equator SST influence on onset may be important because the contrast between land and sea temperatures is small.

\section{Data}

The data used in this study were from rain gauges located within the Brazilian Amazon basin, which are part of the Brazilian National Hydrometeorological network. They were provided by the National Water and Electric Energy Agency of Brazil (ANEEL), whose sources include the ANEEL network, the Brazilian National Institute of Meteorology, the Center for Weather Forecasts and Climate Studies, and some privately owned stations. After setting as missing obviously erroneous reports, data from stations were included if they contained at least $4 \mathrm{yr}$ of data from 1976 to 1997, with no more than $33 \%$ missing during years with data. This resorted in 452 stations being included, which on average contain $13 \mathrm{yr}$ of data, with $13.7 \%$ of the reports missing during years with data. The locations of most of the stations are shown in Marengo et al. (2001). The annual means and analysis of monthly means used in this study extend from January 1976 to December 1997. Unless otherwise noted, results presented below used rainfall from seasons that spanned two calendar years [e.g., Dec-Feb (DJF)] and were obtained from the 21 seasons between 1976/77 and 1996/97; the other seasons contained $22 \mathrm{yr}$ from 1976 to 1997.

In some ways it may be fortuitous (and misleading) that the results to follow depend on observations that begin in the mid-1970s. There is evidence that ENSO impacts over the Americas have been significantly greater since 1976 relative to periods before (M. P. Hoerling 2000, personal communication; Liebmann et al. 2001).

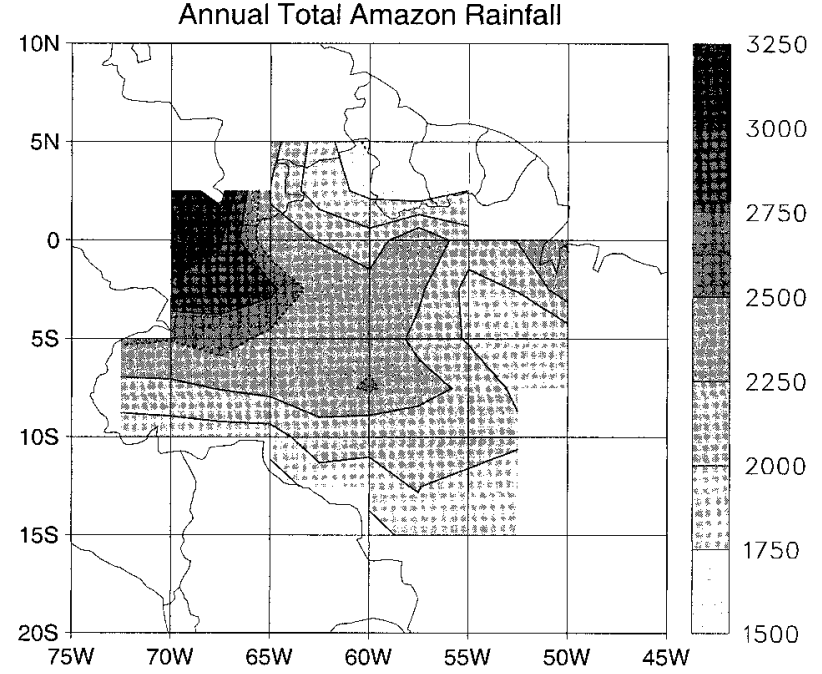

FIG. 1. (a) Climatological annual total precipitation ( $\mathrm{mm}$ ) for period 1976-97. Dotted contour is $2500-\mathrm{mm}$ isoline.

Much of the study employs data that are averaged onto a $2.5^{\circ}$ grid. This is accomplished by averaging all available data for a given day that lie within a circle of $1.8^{\circ}$ centered on each grid point. This technique assumes that there are enough stations averaged into the value at a given grid point so that an occasional missing report does not significantly change the average.

\section{Climatology}

Figure 1 shows the annual mean precipitation in the Brazilian Amazon, obtained from the gridded climatology. Rainfall varies by more than $50 \%$ within Brazilian Amazonia, ranging from less than $2000 \mathrm{~mm}$ in the south, east, and extreme north, to more than $3000 \mathrm{~mm}$ in the northwest, where orographic uplift begins to operate. A secondary maximum near the mouth of the Amazon River is thought to result from nighttime convergence of the easterly trades with the land breeze. Climatologies that combine satellite estimates with gauge observations (e.g., Xie and Arkin 1997) show reasonable agreement in the Amazon on these long timescales, although there is a general tendency for them to be about $10 \%$ high compared to the gauge measurements.

To a first approximation convection in the tropical Americas follows the sun (e.g., Horel et al. 1989). One way to view the seasonality of rainfall is to define the rainfall accumulation quantity $A$.

$$
A(\text { day })=\sum_{n=1}^{\text {day }} R(n)-\bar{R} \times \text { day, }
$$

where $R(n)$ is the daily climatological (or that of a particular year) rainfall as a function of day of year, and $\bar{R}$ is the annual mean daily rainfall. If in every region of interest the rainy season is considered to be the period during which rainfall exceeds its climatological annual 

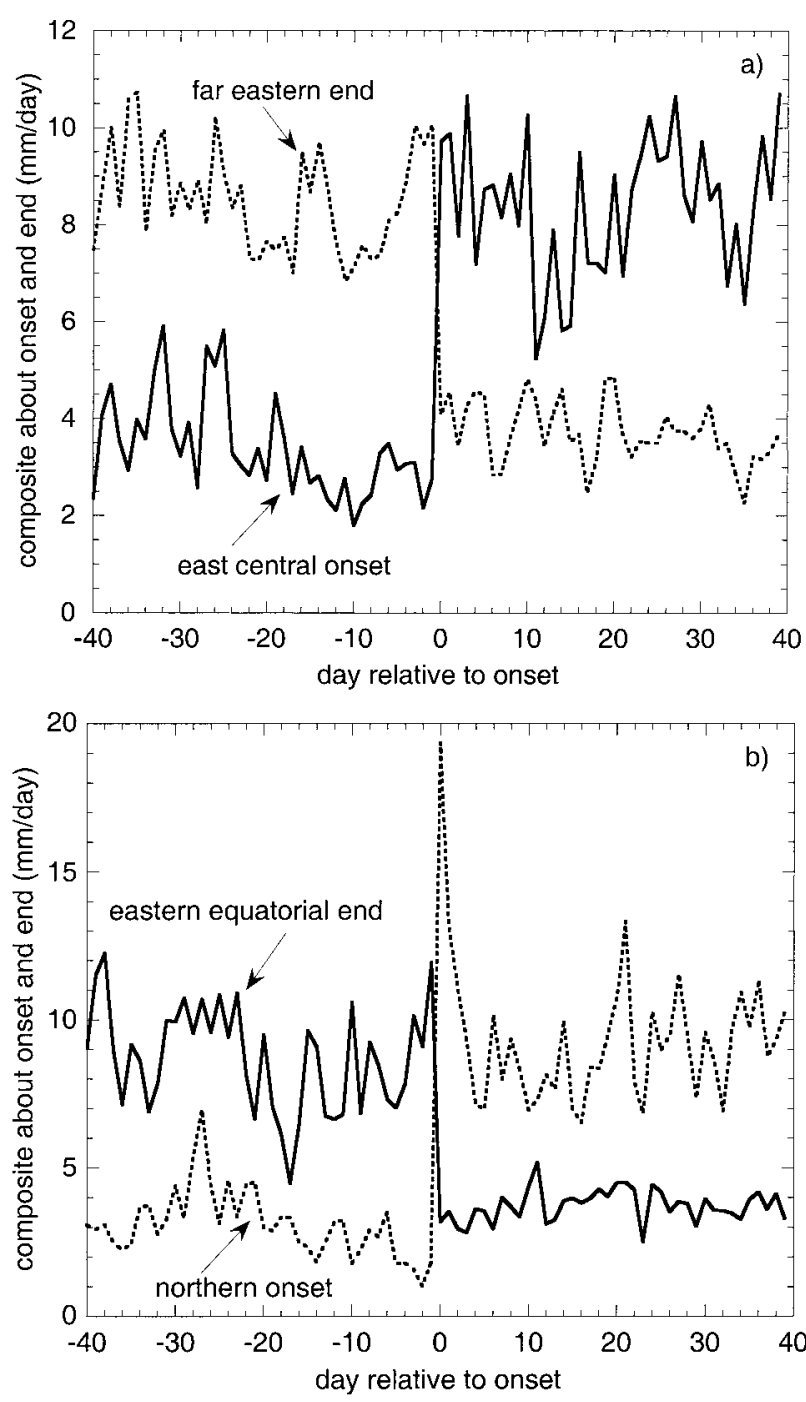

FIG. 2. (a) Composite onset of rainy season for stations in eastcentral Amazon, and end of rainy season for stations in far eastern Amazon. (b) As in (a) except for eastern equatorial end and northern onset. Areas used are discussed in relation to Figs. 7, 8, 9, and 11 .

average, then a positive slope indicates the rainy season. Note that this definition is local because it depends on the climatology in the area of interest.

Composites of onset and end of the rainy season for selected areas to be discussed in detail later, are shown in Fig. 2. The composites are formed after finding onset and end for each year from Eq. (1). In each case the composite signal is one of a sharp increase (decrease) in rainfall at onset (end), suggesting that onset and end are abrupt phenomena, rather than a slow buildup that eventually crosses some arbitrary threshold. In spite of the many years that were averaged into each composite, they are still noisy, with the wettest periods during the dry season occasionally exceeding the driest periods during the wet season.

The climatological starting and ending dates of the
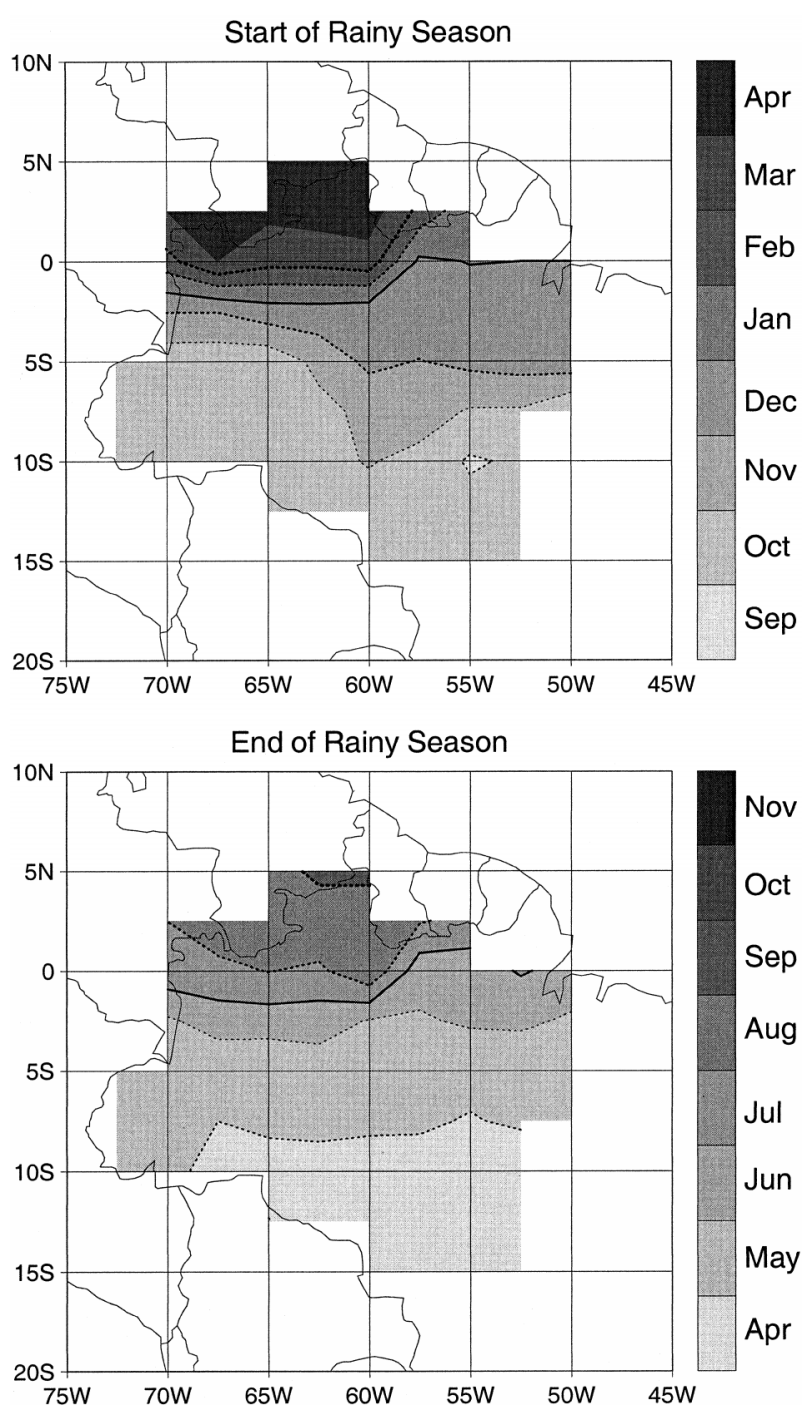

FIG. 3. (a) Start of rainy season from climatological dates. Solid contour represents Dec/Jan division. (b) End of rainy season from climatological dates. Solid contour represents Jun/Jul division. Both start and end are defined by Eq. (1) in text.

wet season, determined from Eq. (1), are shown in Fig. 3. Onset appears to progress from south to north (Fig. $3 a)$. The apparent slow progression of onset near the equator, however, is an artifact of the contouring routine. In reality, onset in the west on the equator and to its north occurs after the March equinox, while to the south onset occurs from the September equinox to the beginning of southern summer.

Marengo et al. (2001) defined Amazon onset and end using a similar dataset averaged into pentads. The definitions of onset and end they used were chosen to be consistent with that used by Kousky (1988), who determined the climatology of onset and end using OLR. Onset (end) was defined as the first pentad with a daily average of more (less) than $4 \mathrm{~mm}$ day $^{-1}$, provided that 6 of the 8 preceding (subsequent) pentads had daily 
December - February Rain Versus Nino 3.4 SST
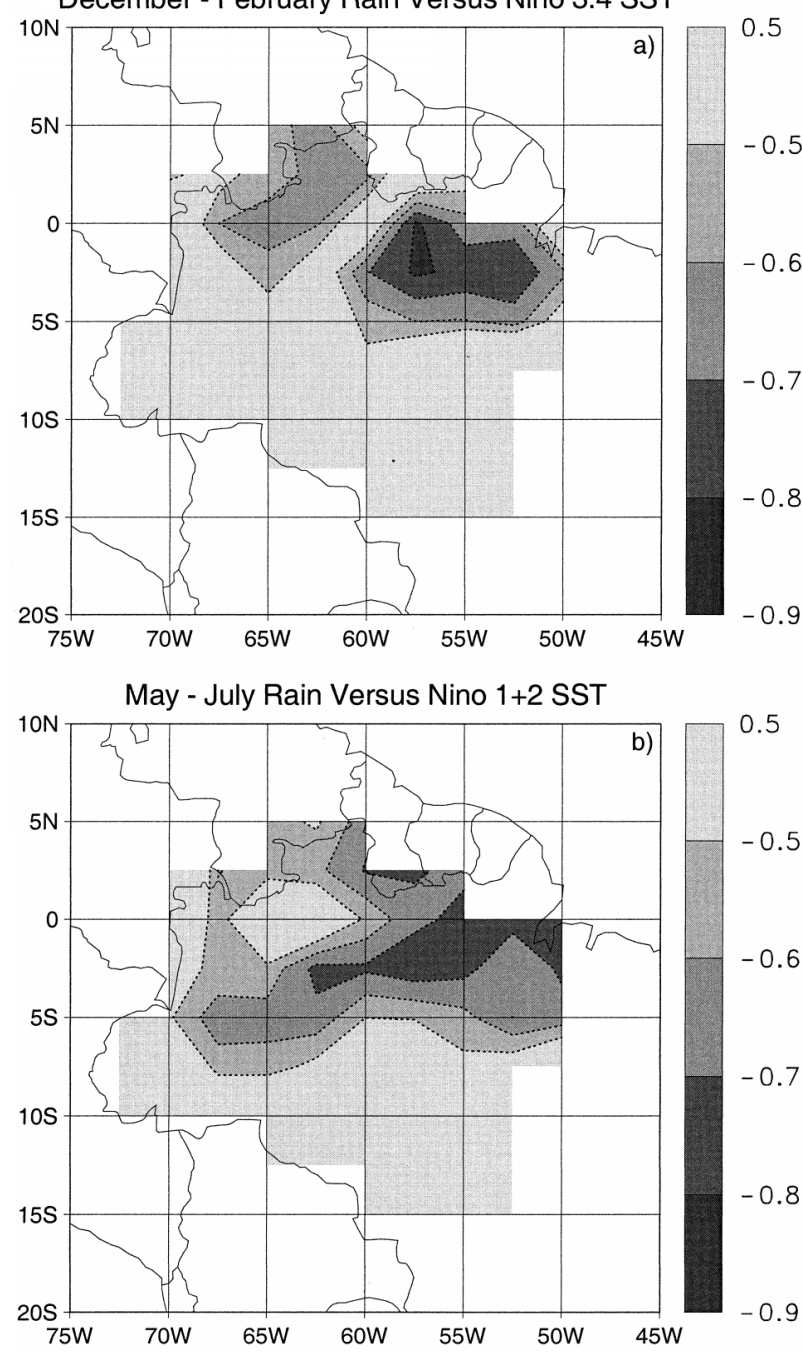

FIG. 4. (a) Simultaneous correlation between DJF SST in Niño-3.4 and rainfall. (b) Simultaneous correlation between MMJ SST in Niño$1+2$ and rainfall.

averages of less than $3.5 \mathrm{~mm} \mathrm{day}^{-1}$, and 6 of the 8 subsequent (preceding) pentads had daily averages of more than $4.5 \mathrm{~mm} \mathrm{day}^{-1}$. One difference between this definition and that used in the present study is that onset is defined uniformly everywhere. Their results for onset were substantially different than those of the present study and are quite sensitive to the threshold chosen. For example, they noted that the sense of onset is reversed when the threshold is doubled. Within a wide range of thresholds, however, onset near the equator is consistent with the present results.

The withdrawal of the rainy season, shown in Fig. $3 \mathrm{~b}$, is smoother than onset. The wet season ends in the south in April, which is the same month that it begins in the far north. In the far north, the wet season ends in September. Therefore there appears to be just a short window during which no part of the Brazilian Amazon

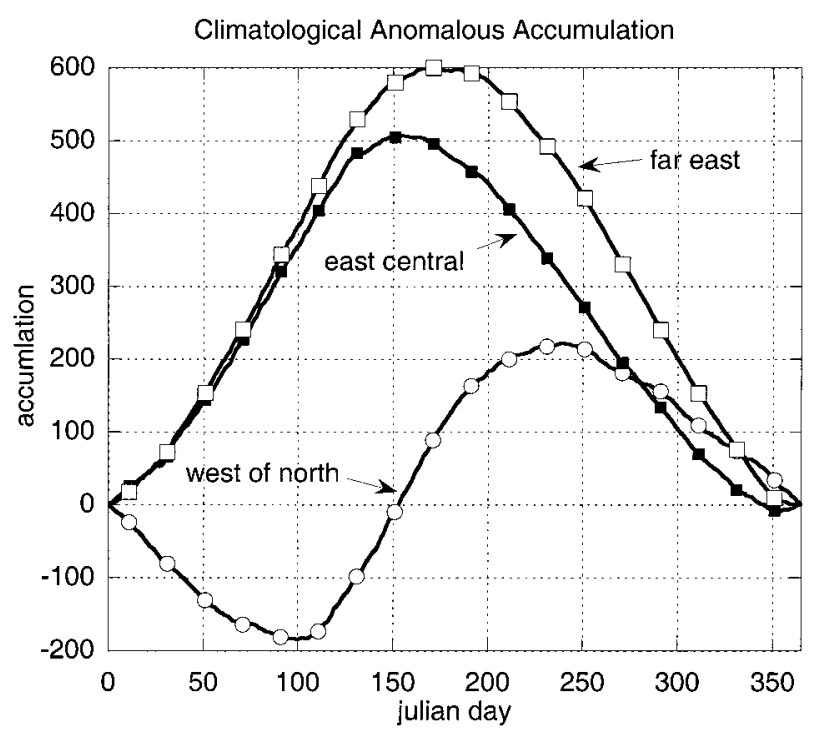

FIG. 5. Climatological anomalous rainfall accumulation [defined by Eq. (1) in text] for different regions of Amazon.

is experiencing its climatological rainy season. The dates of withdrawal agree better with those determined by Marengo et al. (2001) than do the dates of onset. Marengo et al. (2001) found the dates of withdrawal to be relatively insensitive to a change in threshold.

\section{Interannual variability \\ a. Associations with Pacific SST}

As noted, previous studies of rainfall in the Amazon focused on associations with ENSO have suggested a deficit in DJF during its warm phase (i.e., El Niño). Simultaneous correlations for all of the 12 3-month seasons were examined between gridded Brazilian Amazon rainfall and each of the standard SST indices of El Niño (Niño- $1+2=0^{\circ}-10^{\circ} \mathrm{S}, 90^{\circ}-80^{\circ} \mathrm{W}$; Niño-3 $=5^{\circ} \mathrm{N}-5^{\circ} \mathrm{S}$, $150^{\circ}-90^{\circ} \mathrm{W}$; Niño-4 $=5^{\circ} \mathrm{N}-5^{\circ} \mathrm{S}, 160^{\circ} \mathrm{E}-150^{\circ} \mathrm{W}$; Niño$\left.3.4=5^{\circ} \mathrm{N}-5^{\circ} \mathrm{S}, 170^{\circ}-120^{\circ} \mathrm{W}\right)$. Two periods with large correlations (in an absolute sense) emerge. Figure $4 \mathrm{a}$ shows the correlation between DJF rainfall and Niño3.4. Assuming 19 degrees of freedom, the null hypothesis is rejected locally using a two-sided Student's t-test for a correlation of \pm 0.43 . There are two distinct areas in which large negative correlations are evident. One of these is in the eastern-central basin and the other is in the north-northwestern basin (the Amazon basin boundary coincides with the Venezuela-Brazil border). The correlation in the north-northwestern basin is actually largest during November-January when its magnitude approaches that in the east-central basin. The northnorthwest correlation diminishes as indices located farther to the east are used (i.e., Niño-1+2 and Niño-3), while the east-central maximum is quite similar when rainfall is correlated with Niño-3, but weaker using the Niño-4 index. 


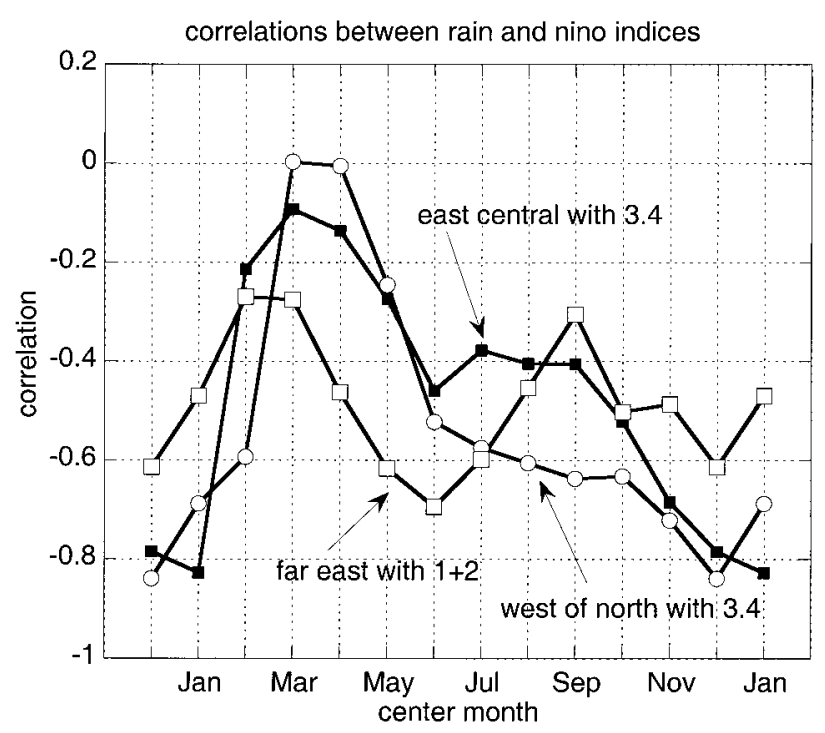

FIG. 6. Simultaneous correlations for each 3-month season between indices of SST and indices of rainfall.

Correlations are also large and negative when Niño$1+2$ is correlated with May-July (MJJ) rainfall (Fig. 4b). They appear to trail into the Amazon from the northeast. These correlations diminish when rainfall is correlated with indices located to the west. There are no large correlations with SST in other parts of the Pacific.

Figure 5 shows curves produced with Eq. (1) for the three areas that show large correlations in Fig. 4. Note that these curves indicate only the timing, and not the amplitude, of the climatological rainy season. The rainy season in the far eastern Amazon lags slightly that in the east-central Amazon. In the east-central Amazon it begins and ends near 15 December and 1 June, while in the east the beginning is near 1 January and the end close to 20 June. In the north-northwest, centered in the Northern Hemisphere, the rainy season begins around 10 April and ends near 30 September.

During the calendar season in which onset or end of the rainy season occurs, invariably there is a strong relationship between rainy season timing and total precipitation, as one would expect. What is less expected is that for 3-month seasons, the timing of the rainy season is at least as important in determining seasonal totals as is the post-onset (or pre-ending) rain rate. This statement is difficult to quantify because as seasons become longer (e.g., 4 months), timing is relatively less important and rate more important, while if the season considered is reduced, then timing is almost everything. As an example, however, in the north-northwest the correlation between March-May (MAM) total rainfall and starting data is -0.78 , while the correlation between the MAM total and the rate (defined as the amount from onset until 31 May divided by the number of days in that period) is 0.43 . The correlation between JAS total rainfall and the ending date is 0.71 , while the correlation between JAS total and the rate (measured from $1 \mathrm{Jul}$ until rainy season end) is 0.30 .

Figure 6 shows simultaneous correlations for each of the twelve 3-month seasons between Niño indices and the area averages of rainfall that exhibited the large correlations shown in Fig. 4. The exact area average rainfall indices were made by averaging individual stations, and chosen to maximize the correlation during the season in which the largest correlations were evident in Fig. 5 (and in maps like Fig. 5 for other seasons and indices). The series of correlations as a function of time are actually quite similar, with the smallest in late northern winter and spring, and the largest during winter, except that the eastern Amazon shows a peak centered on June.

The largest seasonal correlation between east-central rainfall and Niño-3.4 occurs near the climatological onset date for that region. Likewise, the largest correlation in the east with Niño- $1+2$ occurs near the climatological end date. In the north-northwest, however, the largest correlations occur during northern winter, which is completely within the dry season of that region, and there does not appear to be a correspondence between onset or ending and a strong relationship with an index of SST.

The apparent connection between (a) the variation of onset and end of the rainy season and seasonal total rainfall, (b) the observed relationships between onset (and end) and SST (e.g., Marengo et al. 2001), and (c) the peak in correlation between SST and seasonal total rainfall, together suggest that near the equator in the eastern Amazon, the observed relationship between $\mathrm{Pa}-$ cific SST and seasonal total rainfall may in part result from SST's influence on the timing of onset. The following figures illustrate this argument, the presentation of which is the main point of this paper. Figure 7a shows the correlation during DJF between SST and an eastcentral rain index (see caption of Fig. 7). There is a strong relationship between warm eastern Pacific SST and a deficit of rainfall. Figure $7 \mathrm{~b}$ shows the correlation between DJF SST and the east-central onset date. There is a slightly weaker correlation of opposite sign in the approximate same location. The sign is such that warm SSTs are associated with a delayed onset, which is consistent with a deficit of seasonal rainfall in the same situation. On the other hand, when the rain rate (again defined as the rate from onset until the end of Feb) is correlated with DJF SST (Fig. 7c) there is no signal. The period 1982/83 was not included in the calculations of Fig. 7 because the onset data occurred in early March. The similarity between Figs. $7 \mathrm{a}$ and $7 \mathrm{~b}$ suggests that much of the relationship between mean rainfall and SST is due to the relationship between SST and the timing of onset.

Figure 8 shows correlations between MJJ SST and MJJ rainfall in the far eastern Amazon (Fig. 8a), the far eastern Amazon ending date (Fig. 8b), and the far eastern rate from 1 May until rainy season end. The cor- 


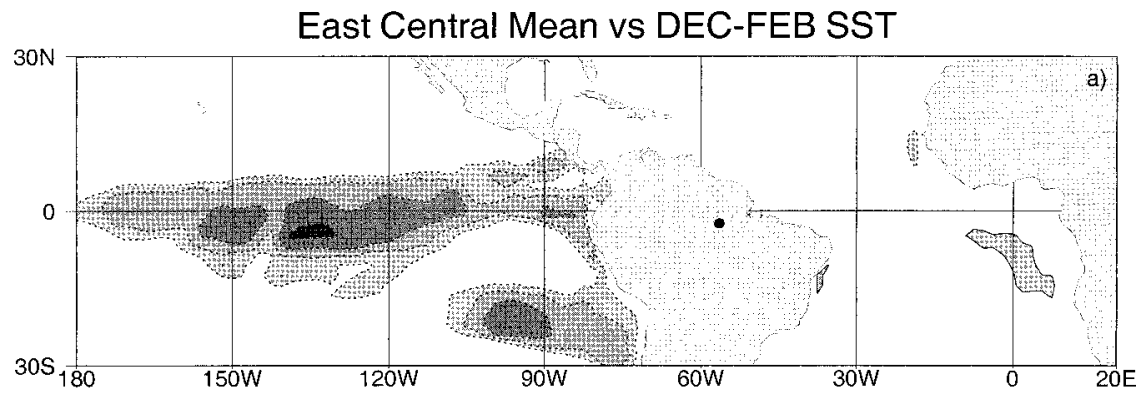

East Central Start vs DEC-FEB SST

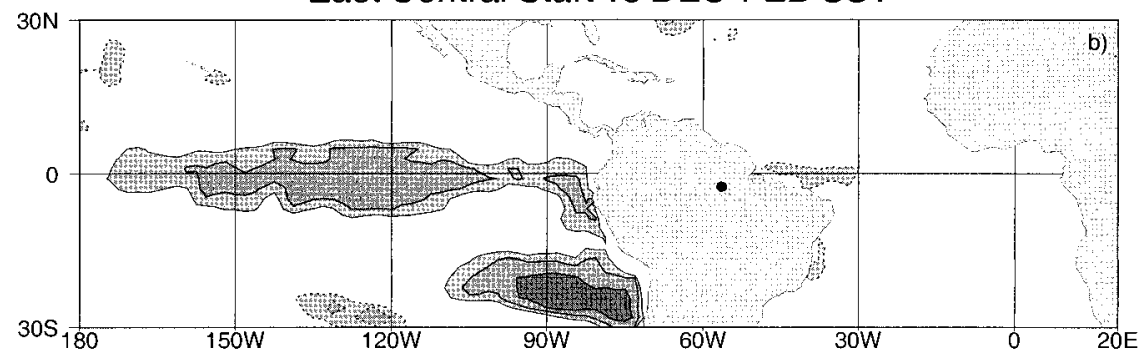

East Central Rate vs DEC-FEB SST

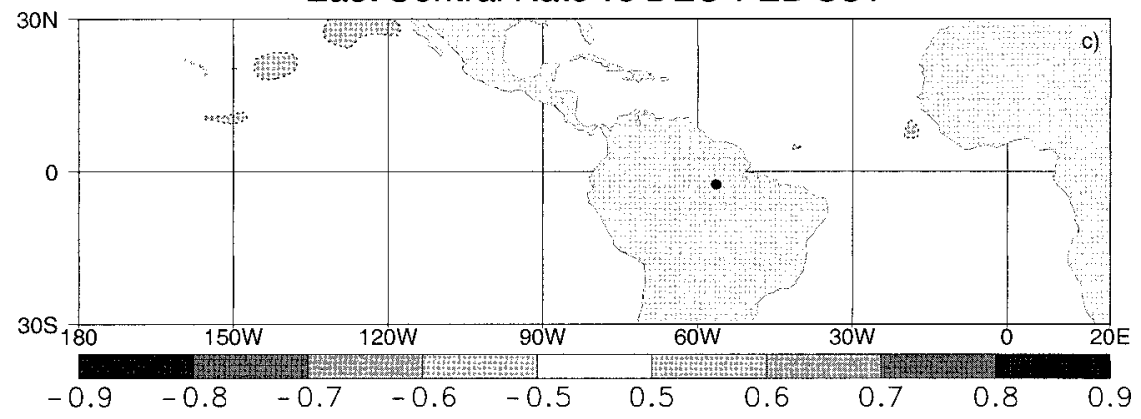

FIG. 7. Correlation between DJF SST and rainfall in east-central Amazon (average of 49 stations from $0^{\circ}$ to $5^{\circ} \mathrm{S}, 59^{\circ}$ to $54^{\circ} \mathrm{W}$, center indicated by dot); (a) DJF mean rainfall, (b) rainy season starting date, and (c) rain rate calculated from start of rainy season through end of Feb. The period 1982-83 is not included in these calculations. Dotted contours indicate negative correlations.

relation with end date is weaker but of the same pattern as is the correlation with mean rainfall. The patterns in the two figures are of the same sign, again consistent with each other, as warm SST is associated with an early withdrawal, and therefore a deficit of rainfall. Both Figs. 7 and 8 suggest the SST influence on timing of the rainy season is an important contributor to its relationship with seasonal total rainfall.

\section{b. Associations with Atlantic SST}

Indices used to characterize tropical Atlantic SST are not as well known as those of the Pacific, although diagnostic indices do exist (e.g., as shown in the Climate Diagnostics Bulletin (CDB), produced by the National Centers for Environmental Prediction). To determine associations between Atlantic SST and rainfall for each 3-month season, rainfall at each grid point is correlated with SST at each grid point, and the max- imum (and minimum) correlation plotted at each SST grid point. The centers of SST usually are near and south of the equator, and during most months the largest tend to be positive. Then SST at the grid points with the largest correlations are correlated with rainfall to determine the areas in which rainfall is best associated with SST.

Two interesting features are present on these maps. The first, located in the south equatorial eastern Atlantic, reaches its maximum in late northern spring and summer and exhibits a slightly weaker peak in northern fall. If an SST index is constructed from SST grid points in this region (which nearly coincides with the $\mathrm{CDB}$ "South Atlantic" index) and then correlated with rainfall (not shown), an area of large correlation appears near the equator and east of $60^{\circ} \mathrm{W}$. An index of eastern equatorial stations (which substantially overlaps the east-central index) has as its mean ending date 13 June.

Figure 9a shows the simultaneous correlation between 
Far Eastern Mean vs MAY-JUL SST

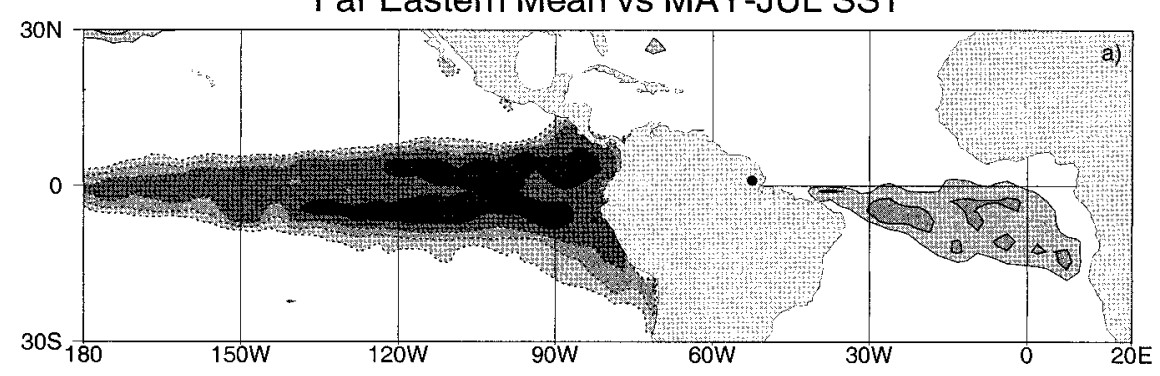

Far Eastern End vs MAY-JUL SST

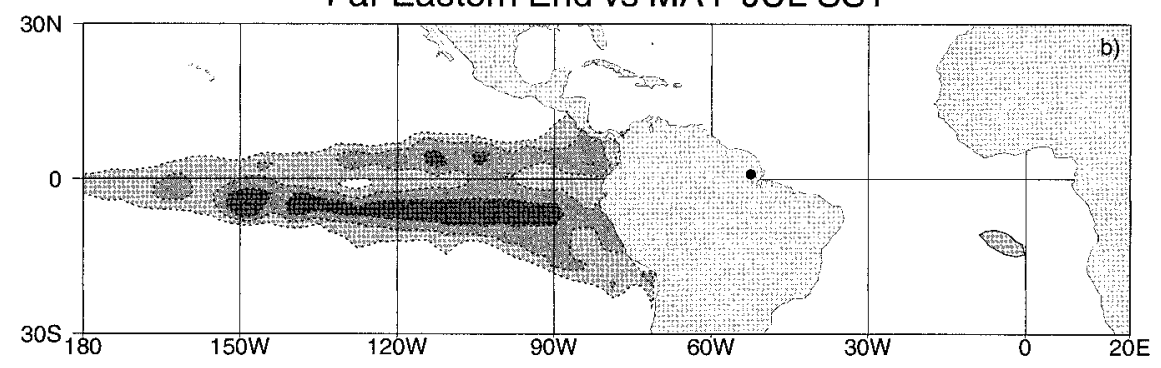

Far Eastern Rate vs MAY-JUL SST

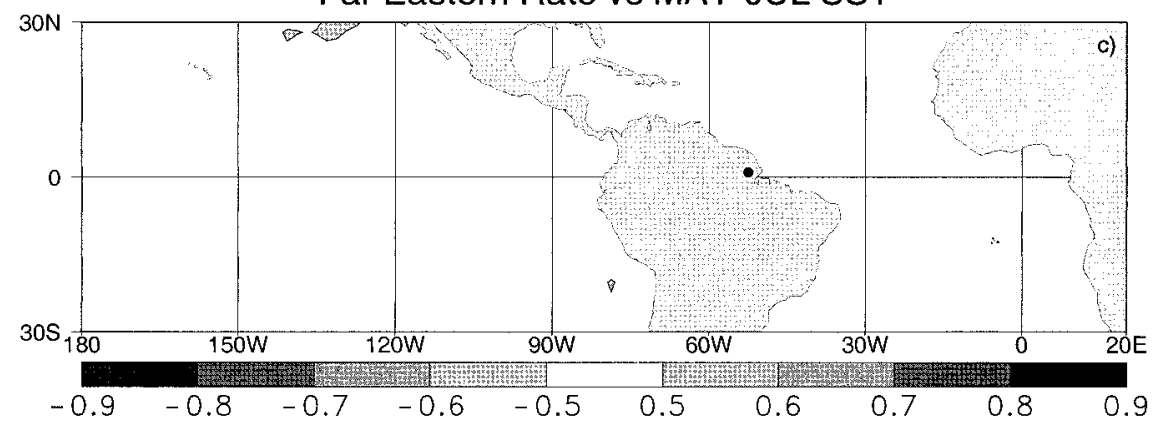

FIG. 8. Correlation between MJJ SST and rainfall in far eastern Amazon (average of 50 stations from $2^{\circ} \mathrm{S}$ to $4^{\circ} \mathrm{N}, 56^{\circ}$ to $49^{\circ} \mathrm{W}$, center indicated by dot); (a) MJJ mean rainfall; (b) rainy season ending date; and (c) rain rate calculated from 1 May through end of rainy season. Dotted contours indicate negative correlations.

the index and SST during April-June (AMJ). The correlations are largest where expected, in the eastern Atlantic, near and south of the equator. The correlation between rainy season ending date and AMJ SST is shown in Fig. 9b. It is quite similar to the correlation with mean rainfall, including the negative correlations in the eastern equatorial Pacific. Thus, the end of the rainy season in the eastern equatorial Amazon is delayed when SSTs are warm in the eastern Atlantic, consistent with an increase in total rainfall. These figures are in sharp contrast to Fig. 9c, which shows the correlation between AMJ SST and the rain rate from 1 April until the end of the rainy season. Again, it appears that the control of SST on total seasonal rainfall is mainly through its control on the timing, rather than on rain rate. The same calculations using MJJ values are nearly identical.

The second peak in correlation is evident during Au-
gust-October (ASO) and September-November (SON). Figure 10 shows the correlation between SON SST and the east-central index (the same as used in Fig. 7). The large correlations are entirely within the dry season in this region. The remarkable aspect of this figure is the huge change in correlation from this season to the DJF season (Fig. 7a). From one 3-month season to the next independent season, the correlations range from large positive correlations in the Atlantic, to large negative correlations in the Pacific.

The other area of interest in the Atlantic has the largest correlation with Amazon rainfall during FebruaryApril (FMA), is centered in the western Atlantic, and is negatively correlated with rainfall in the northern Amazon. The correlation between an index of stations and SST is shown in Fig. 11a. For this index, the average starting date is 22 March. The correlation between starting date and FMA SST (Fig. 11b) again is similar to 

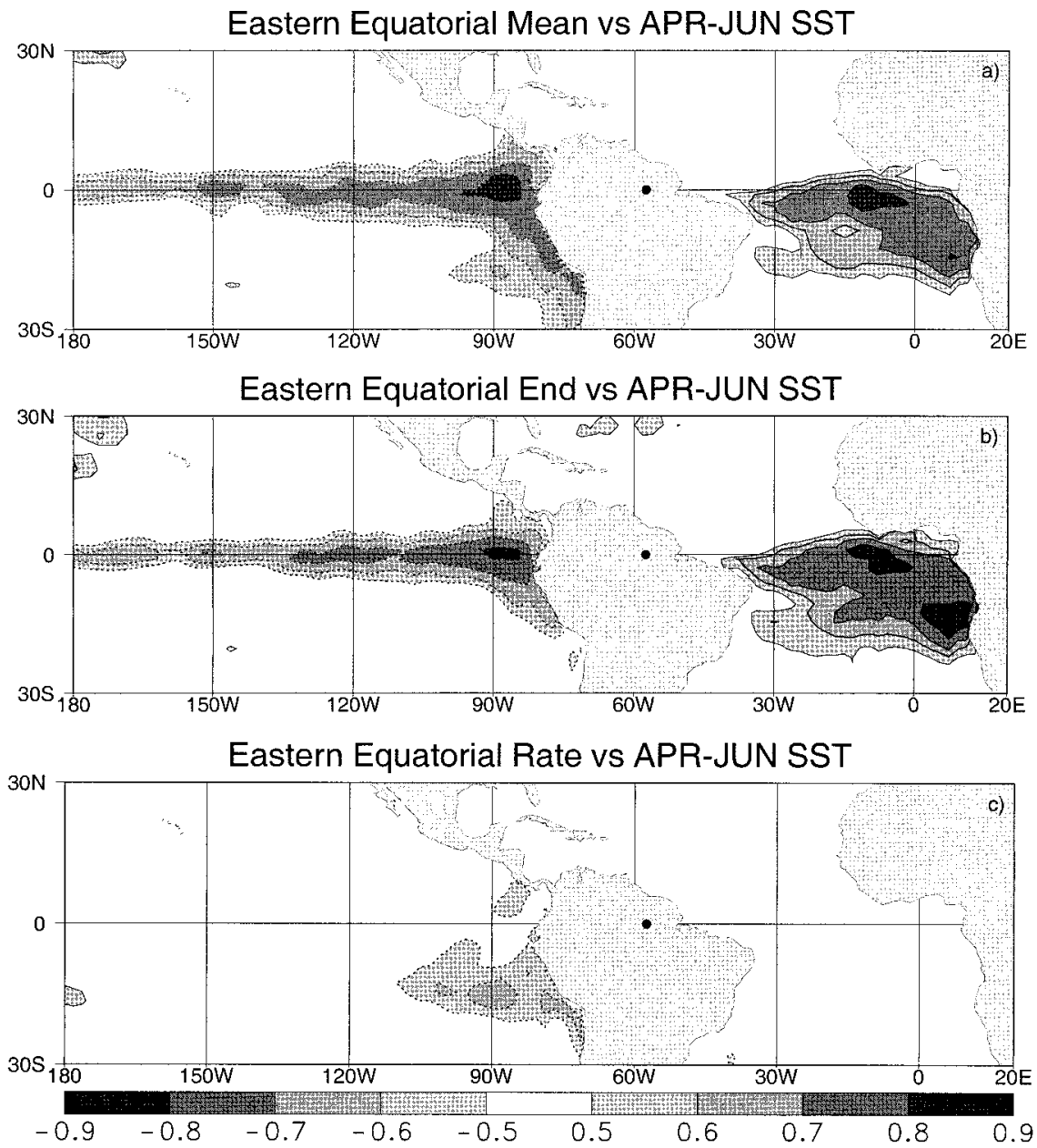

FIG. 9. Correlation between AMJ SST and rainfall in eastern equatorial Amazon (average of 20 stations from $2.5^{\circ} \mathrm{S}$ to $2.5^{\circ} \mathrm{N}, 60^{\circ}$ to $55^{\circ} \mathrm{W}$; center indicated by dot), (a) mean rainfall; (b) eastern equatorial rainy season ending date; and (c) far eastern rain rate calculated from 1 Apr to the end of the rainy season. Dotted contours indicate negative correlations.

the correlation with mean rainfall, while there is little signal when SST is correlated with the postonset (until the end of Apr) rain rate (Fig. 11c).

In the Atlantic, more so than in the Pacific, the areas of association with Amazon rainfall were determined by an objective search for the best correlation, rather than by some a priori expectation. Thus the possibility exists that the large correlations documented are a result

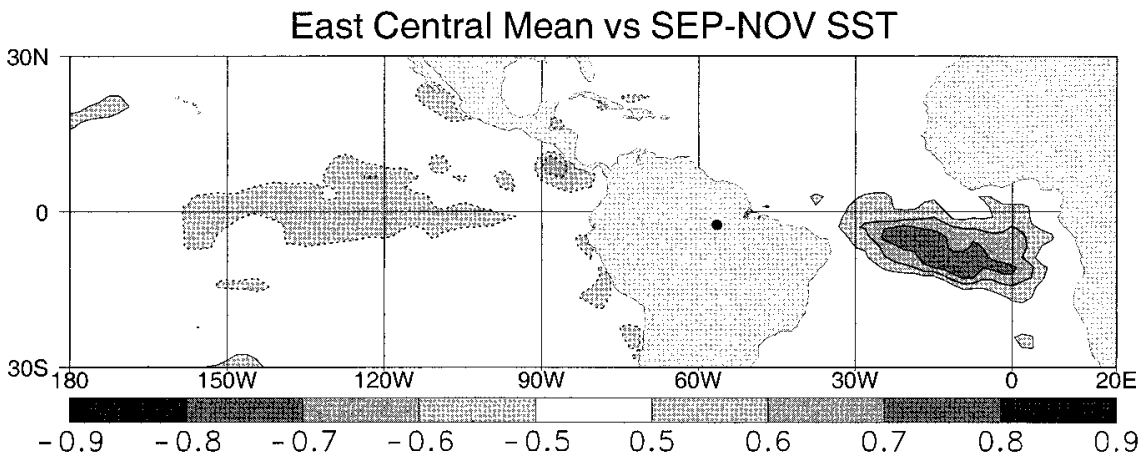

FIG. 10. Simultaneous correlation between SON SST and east-central rainfall (same average as used in Fig. 7). Dotted contours indicate negative correlations. 

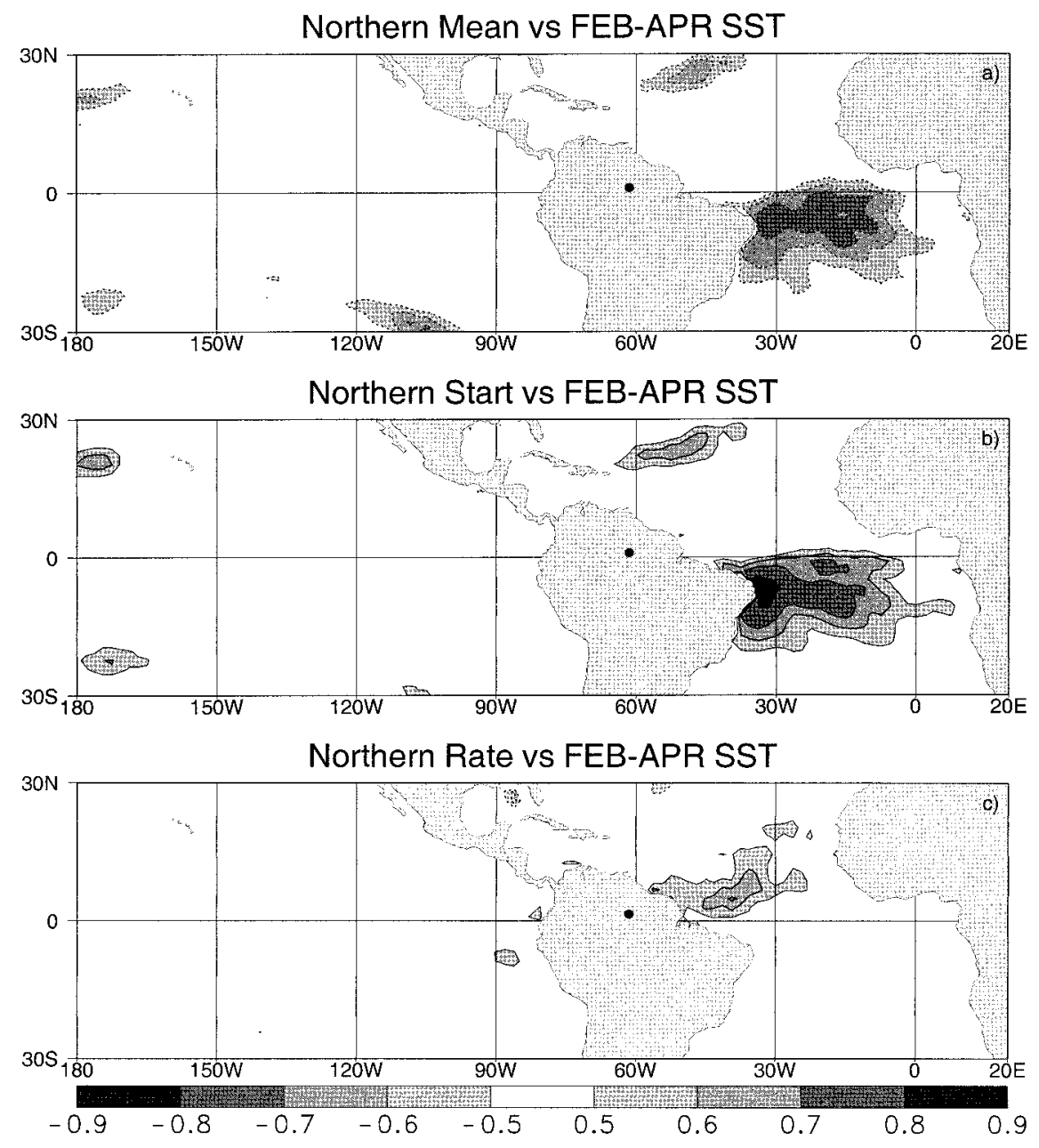

FIG. 11. Correlation between AMJ SST and rainfall in northern Amazon (average of 12 stations from $1^{\circ} \mathrm{S}$ to $3^{\circ} \mathrm{N}, 63^{\circ}$ to $60^{\circ} \mathrm{W}$; center indicated by dot); (a) mean rainfall; (b) northern rainy season starting date; and (c) northern rain rate calculated from start through 30 Apr. Dotted contours indicate negative correlations.

of chance rather than any physical relationship, although on the large scale, previous studies have drawn consistent conclusions (e.g., Marengo 1992; Rao et al. 1996).

To address the question of statistical relevance, a technique inspired by Livezey and Chen (1983) is employed. For each of the seasons shown during which large correlations emerge between Atlantic SST and rainfall, 200 pairs of maximum and minimum correlation maps are generated by correlating the rainfall at each grid point with randomized SST fields. Then the number of grid points in the Atlantic between $20^{\circ} \mathrm{N}$ and $20^{\circ} \mathrm{S}$ on each map that exceed an absolute value of 0.7 are compared with same count on the original map. The results are that the large positive correlations that emerge during AMJ and SON exceed all but $1 \%$ of the randomized maps, but that the negative correlations during FAM are only marginally statistically relevant.

\section{Summary and discussion}

The point of this paper is to argue that the observed association in the Amazon basin between seasonal rainfall totals and SST is often at least partly due to the influence of SST on the timing of the rainy season. Analyses are presented in support of this hypothesis.

A search is conducted for simultaneous linear correlations between 3-month seasons of SST and rainfall in the Brazilian Amazon basin. Correlations can be quite large, but are regional in extent.

In the Pacific, simultaneous correlations with seasonal rainfall are always negative. The only large (in an absolute sense) correlations are between SST in the central to eastern equatorial Pacific (in the region associated with El Niño) and rainfall in the eastern equatorial Amazon (east of $60^{\circ} \mathrm{W}$ and south of the equator) and in the north-northwestern Amazon (west of $60^{\circ} \mathrm{W}$ and centered 
north of the equator). In both cases the largest correlations are observed in southern summer.

SST in the Atlantic is correlated with rainfall in the same vicinity as that in the Pacific, but during different seasons. SST in the eastern equatorial South Atlantic is positively correlated with rainfall in the eastern Amazon during northern spring and fall. SST in the central and western south equatorial Atlantic is negatively correlated with rainfall in the northern Amazon in late southern summer.

In all regions of the Brazilian Amazon that exhibit large correlations with SST, the large correlations are present during either the season that is the transition between wet and dry (or dry and wet), or during the dry season. It is shown that in the areas that exhibit large correlations during the transition seasons, SST influences the timing of the rainy season in a manner consistent in pattern and sign with the correlation with seasonal total rainfall. The intensity of rainfall entirely within the wet season does not appear to be related to SST anomalies.

The signs of the correlations during transition seasons suggest that warm Pacific SSTs delay the seasonal transition of convection into the eastern Amazon, and to a lesser extent, hasten its withdrawal. Warm eastern equatorial South Atlantic SSTs delay its withdrawal. Warm western equatorial South Atlantic SSTs delay transition into the western Brazilian Amazon, with the strongest signal north of the equator.

In southern summer there is also an area of large negative correlations with rainfall in the north-northwest, which is entirely within the dry season there. SSTs in the south equatorial eastern Atlantic are positively correlated with rainfall in the east-central Amazon, which is also within the dry season.

As with any study there is a certain amount of subjectivity involved in which results to shown and points to emphasize. We have tried to be honest by first choosing areas with the largest correlations, and then computing the correlations with onset or end date, and preor postonset rain rate. While we are confident that the timing of onset is influenced by SST and weighs heavily in determining seasonal totals, our confidence in the reality of the apparent lack of signal in rain rate wanes slightly.

One problem with the correlation with rain rate from onset until a certain date (or from a certain date until end) is that during some years the rainy season so defined can be quite short, and over a short period of time there is undoubtedly a random element to rainfall. We have tried to mitigate this problem where possible. For example, although correlations were shown in Fig. 8 with eastern Amazon rainfall during AMJ, the correlations with total rainfall and onset during MJJ are actually slightly larger than during AMJ. Since the earliest ending date is near the beginning of May, however, it was deemed better to do the calculations from April, thus allowing at least 30 days from which to calculate the rain rate. It has also been argued that one should base calculations on a sliding rainy season in which both onset and end vary, rather than defining 3-month seasons. This, however, introduces another variable that makes interpretation more difficult.

It is our intent to examine onset and end of the rainy season in a general circulation model (GCM). The hypothesis is that the modest skill seen in GCMs is a result of the SST-timing relationship, and that in areas that onset is affected by SST, prediction of seasonal totals will improve if the total is regressed from the predicted onset date, rather than taken directly from the GCM.

Acknowledgments. The authors wish to thank both reviewers for their useful suggestions, and acknowledge support from Grant GC99-423 from the NOAA Pan American Climate Studies Program, which provided partial salary support to BL. JAM also acknowledges the Conselho Nacional de Pesquisas (CNPq) of Brazil for partial support.

\section{REFERENCES}

Aceituno, P., 1988: On the functioning of the Southern Oscillation in the South American sector. Part I: Surface climate. Mon. Wea. Rev., 116, 505-524.

Dettinger, M., D. Cayan, G. McCabe, and J. Marengo, 2000: Multiscale ENSO variability and hydrological systems. El Niño: Multiscale Variability and Its Impacts on Natural Ecosystems and Society, H. Diaz and V. Markgraf, Eds., Cambridge University Press, in press.

Figueroa, S. N., and C. A. Nobre, 1990: Precipitation distribution over central and western tropical South America. Climanálise, 6, 36-40.

Fu, R., B. Zhu, and R. E. Dickinson, 1999: How do atmosphere and land surface influence seasonal changes of convection in the tropical Amazon? J. Climate, 12, 1306-1321.

_, M. Chen, W. Li, and R. E. Dickinson, 2001: How do tropical sea surface temperatures influence the seasonal distribution of precipitation in the equatorial Amazon? J. Climate, 14, 40034026.

Horel, J. D., A. N. Hahmann, and J. E. Geisler, 1989: An investigation of the annual cycle of convective activity over the tropical Americas. J. Climate, 2, 1388-1403.

Kayano, M., and A. D. Moura, 1986: O El Niño 1982-83 e a precipitacão sobre a America do Sul. Rev. Brasil. Geofis., 4, 291214.

Kiladis, G. N., and H. F. Diaz, 1989: Global climatic anomalies associated with extremes in the Southern Oscillation. J. Climate, 2, 1069-1090.

Kousky, V. E., 1988: Pentad outgoing longwave radiation climatology for the South American sector. Rev. Brasil. Meteor., 3, 217-231.

_ , and C. F. Ropelewski, 1989: Extremes in the Southern Oscillation and their relationship to precipitation anomalies with emphasis on the South American region. Rev. Brasil. Meteor., 4, 353-363.

_ - M. T. Kagano, and I. F. A. Cavalcanti, 1984: A review of the Southern Oscillation: Oceanic-atmospheric circulation changes and related rainfall anomalies. Tellus, 36A, 490-504.

Liebmann, B., C. Jones, and L. M. V. de Carvalho, 2001: Interannual variability of daily extreme precipitation events in the state of São Paulo, Brazil. J. Climate, 14, 208-218.

Livezey, R. E., and W. Y. Chen, 1983: Statistical field significance and its determination by Monte Carlo techniques. Mon. Wea. Rev., 111, 46-59. 
Marengo, J. A., 1992: Interannual variability of surface climate in the Amazon Basin. Int. J. Climatol., 12, 853-863.

1995: Interannual variability of deep convection over the tropical South American sector as deduced from ISCCP C2 data. Int. J. Climatol., 15, 995-1010.

_ _ and S. Hastenrath, 1993: Case studies of extreme climatic events in the Amazon basin. J. Climate, 6, 617-627.

- and C. A. Nobre, 2000: The hydroclimatological framework of Amazonia. Biogeochemistry of Amazonia, J. Richey, M. MacClaine, and R. Victoria, Eds., Cambridge University Press, in press.

, I. Druyan, and S. Hastenrath, 1993: Observational and modeling studies of Amazonia interannual climate variability. Climatic Change, 23, 267-286.

_, B. Liebmann, V. E. Kousky, N. P. Filizola, and I. C. Wainer, 2001: Onset and end of the rainy season in the Brazilian Amazon basin. J. Climate, 14, 833-852.

Obregon, G., and C. A. Nobre, 1990: Principal Component Analysis applied to rainfall in Amazonia. Climanálise, 5, 35-46.

Rao, V. B., and K. Hada, 1990: Characteristics of rainfall over Brazil:
Annual variations and connections with the Southern Oscillation. Theor. Appl. Climatol., 42, 81-91.

- I. I. Cavalcanti, and K. Hada, 1996: Annual variation of rainfall over Brazil and water vapor characteristics over South America. J. Geophys. Res., 101, 26 539-26 551.

Rogers, J. C., 1988: Precipitation variability over the Caribbean and tropical Americas associated with the Southern Oscillation. J. Climate, 1, 172-182.

Ropelewski, C. F., and M. S. Halpert, 1987: Global and regional scale precipitation patterns associated with the El Niño/Southern Oscillation. Mon. Wea. Rev., 115, 1606-1626.

$\longrightarrow$, and — 1989: Precipitation patterns associated with the high index phase of the Southern Oscillation. J. Climate, 2, 268-282.

Wagner, R. G., 1996: Decadal-scale trends in mechanisms controlling meridional sea surface temperature gradients in the tropical Atlantic. J. Geophys. Res., 101 (C7), 16 683-16 694.

Xie, P., and P. A. Arkin, 1997: Global Precipitation: A 17-year monthly analysis based on gauge observations, satellite estimates, and numerical model outputs. Bull. Amer. Meteor. Soc., 78, 25392558. 